\title{
Characterization of TiAl-Be Alloys Produced by Electric Current Activated Sintering
}

\author{
N. ERGIN*, O. OzDEMIR \\ Sakarya University, Technology Faculty, Department of Metallurgy and Materials Engineering, \\ 54187 Esentepe Campus, Sakarya, Turkey
}

\begin{abstract}
In this study, TiAl-Be intermetallic alloys were produced by electric current-activated sintering (ECAS) method in open air under the uniaxial pressure of $200 \mathrm{MPa}$ at a current of 1100-1200 A, applied for 2 minutes. Aluminum powder with $15 \mu \mathrm{m}$ size $(99 \%)$, titanium powder with less than $45 \mu \mathrm{m}$ size $(99.5 \%)$ and beryllium powder with size less than $44 \mu \mathrm{m}$ size $(99 \%)$ were used in order to produce the samples. The elemental powders were mixed in the stoichiometric ratio of 1:1, corresponding to molar proportion of TiAl intermetallic phases, and then the mixed powders were synthesized. While three phases were found in the TiAl samples after the microstructural examination, multi-phases were observed in the TiAl-5 wt.\% Be samples. XRD studies revealed that the TiAl intermetallic alloys include $\mathrm{TiAl}, \mathrm{Ti}_{3} \mathrm{Al}$ and $\mathrm{TiAl}_{3}$ phases. In addition to these three phases, $\mathrm{Be}_{2} \mathrm{Ti}$ phase was also found in the TiAl-5 wt.\% Be alloys. The relative densities of the TiAl and TiAl-5 wt.\% Be samples, measured according to Archimedes' principle, were approximately $96.4 \%$ and $94.5 \%$. Micro-hardness of TiAl and TiAl-5 wt.\% Be samples was approximately $426 \pm 34$ and $478 \pm 62 \mathrm{HV}_{0.1}$, respectively.
\end{abstract}

DOI: $10.12693 /$ APhysPolA.127.1103

PACS: 81.05.Bx, 81.20.Ev, 81.40.Cd

\section{Introduction}

Intermetallic compounds, especially aluminides have been the subject of scientific interest for more than 20 years because of their attractive physical, thermal, and mechanical properties. Among these, ordered intermetallic alloys based on TiAl are considered as next-generation high-temperature structural material in the aerospace and automotive fields because of the low density (3.7$\left.4.1 \mathrm{~g} / \mathrm{cm}^{3}\right)$, high melting point $\left(1460{ }^{\circ} \mathrm{C}\right)$, high specific stiffness, superior high-temperature strength and excellent high temperature oxidation and burn resistance. However, their applications are hindered by relatively low room temperature ductility, poor fracture toughness and bad hot workability. In the last decades, considerable efforts such as alloying with ternary or more complex alloying additions, heat treatment, suitable fabrication technique, thermo-mechanical treatment have been devoted to improving these properties [1-6].

A number of methods have been utilized in the synthesis and processing of TiAl based alloys, such as Vacuum Arc Remelting (VAR), conventional melting, casting processes and hot working techniques (forging, extrusion, etc). In these manufacturing routes, one of the main problems is the scattering in mechanical properties due to the segregation in the composition. Powder metallurgy is an interesting alternative to control the composition. Electric current activated sintering (ECAS) is a class of consolidation methods in which mechanical pressure is combined with electric and thermal fields, to enhance in-

*corresponding author; e-mail: nergin@sakarya.edu.tr terparticle bonding and densification. Some of the advantages of ECAS technique are higher heating rates, improved microstructure (smaller grain size), and fully densified materials at lower temperatures. In particular, lower temperatures and shorter processing times give the possibility to sinter nanometric or metastable powders to near theoretical density with little grain growth or retention of metastability and cleaned grain boundaries. Moreover, due to the shorter processing time, air sintering is often appropriate, with no need of controlled environments. Furthermore, due to its characteristics, fully sintered parts of uniform density, close or equal to theoretical, or of controlled porosity, can be produced by ECAS process, very rapidly, to near final configuration, with very low rejection rates of the produced objects $[7-9]$.

In this paper, $\mathrm{TiAl}$ intermetallic alloy was produced by electric current-activated sintering and effect of the addition 5 wt.\% Be to the alloy was investigated. The microstructures and phase constitutions were characterized by scanning electron microscopy (SEM-EDS) and X-ray diffraction (XRD). The relative densities of test materials were measured according to Archimedes' principle. Microhardness of sintered test materials was determined by using micro-hardness tester.

\section{Experimental details}

Titanium powder (99.5\% purity, less than $45 \mu \mathrm{m})$, aluminum powder (99\% purity, $15 \mu \mathrm{m}$ ) and beryllium powder $(99 \%$ purity, less than $44 \mu \mathrm{m})$ were used as starting materials in order to manufacture TiAl and TiAl-5 wt.\% $\mathrm{Be}$ intemetallic alloys. $\mathrm{Ti}$ and $\mathrm{Al}$ powders were mixed in stoichiometric ratio corresponding to the TiAl intermetallic phase, in a molar proportion of 1:1. The powders 
including 5 wt.\% Be as the alloying element were mixed. Prior to sintering, the mixture was pressed into a cylindrical compact in a metal die, coated with a thin layer of boron nitride, under a uniaxial pressure of $200 \mathrm{MPa}$. The diameter and height of the compact samples were $15 \mathrm{~mm}$ and $5 \mathrm{~mm}$, respectively. The production of TiAl and TiAl-Be intermetallic alloys was performed by electric current-activated sintering at 1100-1200 A for 2 minutes.

The samples for metallographic examination were subjected to grinding with sandpaper with 80, 320, 600, 1000 and 1200 grit and then polishing by means of polishing cloth with fine alumina powder with size of 0.3 micron. The microstructures and phase constitution were characterized by SEM-energy dispersive spectroscopy (SEM-EDS) and XRD. The relative density and porosity of the synthesized sample were measured using Archimedes' method. Microhardness of sintered samples was determined by using micro-hardness tester with a load of $100 \mathrm{~g}$ for $10 \mathrm{~s}$ on a polished cross-sectional area of test materials.
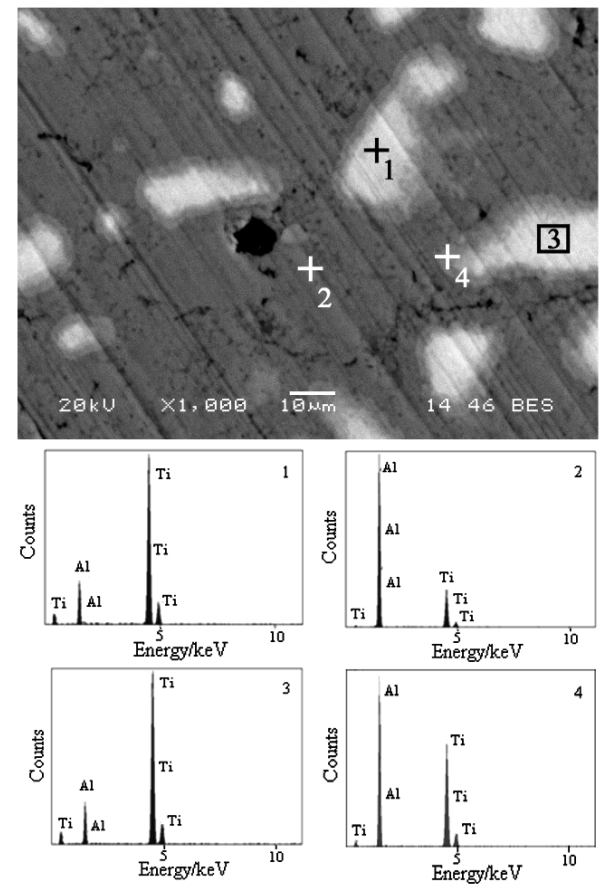

Fig. 1. SEM image and EDS analysis of TiAl intermetallic alloys.

\section{Results and discussion}

Figures 1 and 2 show the microstructure and distribution of alloying elements in the TiAl and TiAl-5 wt.\% $\mathrm{Be}$ intermetallic alloys produced by electric currentactivated sintering method. According to the analysis (Fig. 1), it was observed that white region of $\mathrm{Ti}-$ based phases (mark 1 and 3), matrix of Al-based phases (mark 2) and grey region of $\mathrm{Ti}-\mathrm{Al}$ phases (mark 4) were observed. These SEM images reveal that the TiAl intermetallics have three phase microstructure, whereas TiAl$5 \mathrm{wt} . \%$ Be samples have multi-phase.
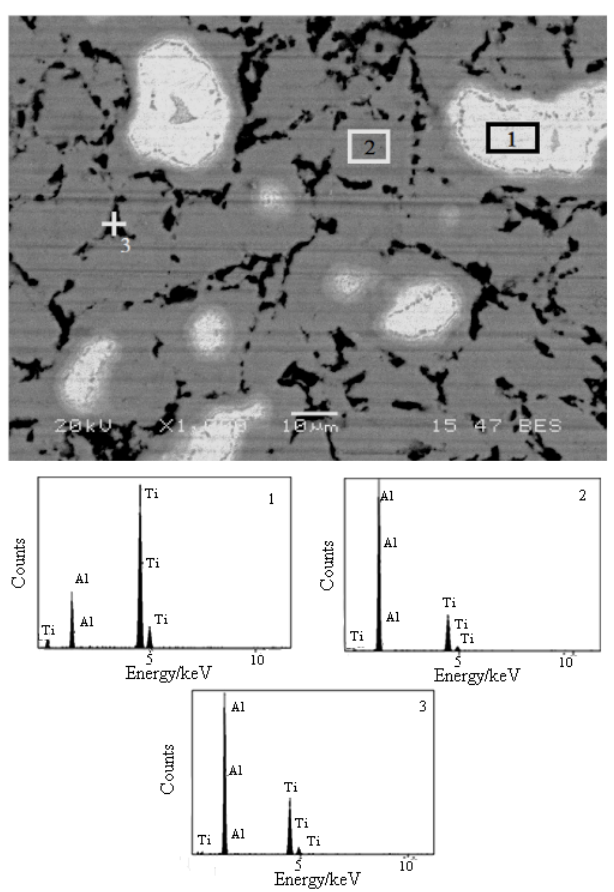

Fig. 2. SEM image and EDS analysis of TiAl5 wt. \%Be intermetallic alloys.

While $\mathrm{TiAl}, \mathrm{Ti}_{3} \mathrm{Al}$ and $\mathrm{TiAl}_{3}$ phases in the $\mathrm{Ti}-\mathrm{Al}$ intermetallic alloys were determined by XRD analysis (Fig. 3), in the TiAl-5 wt.\% Be sample, $\mathrm{Be}_{2} \mathrm{Ti}$ phase was determined in addition to $\mathrm{TiAl}, \mathrm{Ti}_{3} \mathrm{Al}$ and $\mathrm{TiAl}_{3}$ phases (Fig. 4).

The hardness of the TiAl and TiAl-5 wt.\% Be intermetallic alloys, measured using Vickers indentation technique, with a load of $100 \mathrm{gr}$, were approximately $426 \pm 34$ and $478 \pm 62 \mathrm{HV}_{0.1}$, respectively. The relative densities, calculated according to Archimedes' principle, of the TiAl and TiAl-5 wt.\% Be samples were approximately $96.4 \%$ and $94.5 \%$ respectively.

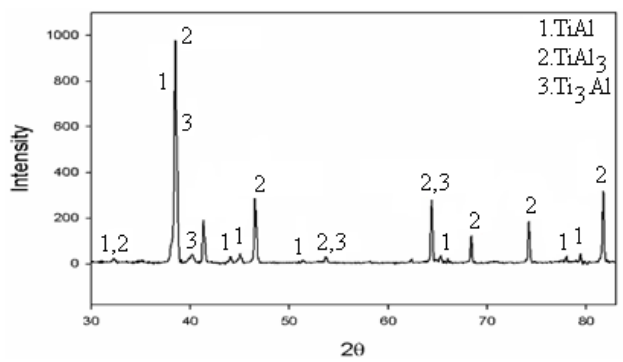

Fig. 3. XRD analyses of TiAl intermetallic alloys.

\section{Conclusions}

The following results can be derived from present study:

1. The XRD analysis of Ti-Al samples indicates presence of $\mathrm{TiAl}, \mathrm{Ti}_{3} \mathrm{Al}, \mathrm{Al}_{3} \mathrm{Ti}$ phases, whereas $\mathrm{TiAl}-$ 5 wt.\% Be samples consist of TiAl, $\mathrm{Ti}_{3} \mathrm{Al}, \mathrm{Al}_{3} \mathrm{Ti}$, $\mathrm{Al}_{2} \mathrm{O}_{3}$ and $\mathrm{Be}_{2} \mathrm{Ti}$ phases. 


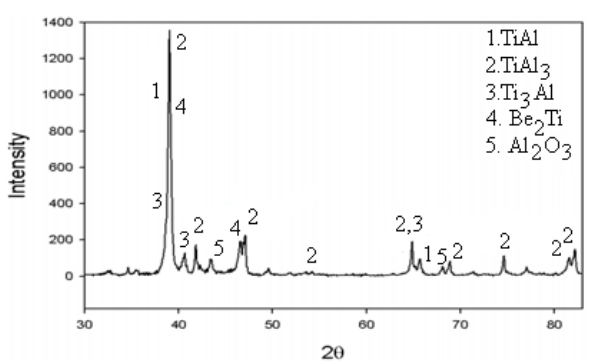

Fig. 4. XRD analyses of TiAl-5 wt.\% Be intermetallic alloys.

2. The relative densities of the $\mathrm{TiAl}$ and $\mathrm{TiAl}-5$ wt.\% Be samples, calculated according to Archimedes' principle, were approximately $96.4 \%$ and $94.5 \%$ respectively.

3. The hardness of the TiAl and TiAl-5 wt.\% Be intermetallic alloys was approximately $426 \pm 34$ and $478 \pm 62 \mathrm{HV}_{0.1}$ respectively.

\section{References}

[1] Y. Song, R. Yang, D. Li, Z.Q. Hu, Z.X. Guo, Intermetallics 8, 563 (2000).

[2] D. Pilone, F. Felli, A. Brotzu, Intermetallics 43, 131 (2013).

[3] Y.Huang, Y. Wang, H. Fan, J. Shen, Intermetallics 31, 202 (2012).

[4] Y. Chen, H. Niu, F. Kong, S. Xiao, Intermetallics 19, 1405 (2011).

[5] Z. Xie, T. Gao, X. Guo, X. Qin, Q. Xie, Physica B 440, 130 (2014).

[6] W. Deng, Y.Y. Huang, D.H. Wu, M.Z. Cao, L.Y. Xiong, Materials Letters 56, 593 (2002).

[7] M.A. Lagos, I. Agote, Intermetallics 36, 51 (2013).

[8] S. Grasso, Y. Sakka, G. Maizza, Sci. Technol. Adv. Mater. 10, 053001 (2009).

[9] R. Orru, R. Licheri, A.M. Locci, A. Cincotti, G. Cao, Materials Science and Engineering R 63, 127 (2009). 